\title{
DISLOCATION NONLINEAR DYNAMICS AND CRYSTAL SONOLUMINESCENCE
}

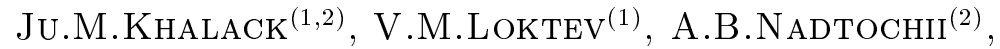 \\ I.V.OstrovskiI ${ }^{(2)}$, H.-G.WALteR ${ }^{(3)}$ \\ (1) Bogolyubov Institute for Theoretical Physics, \\ National Academy of Sciences of Ukraine, \\ 14-b Metrologichna Str., Kyiv 252143, Ukraine \\ (2) T.Shevchenko Kyiv National University \\ 6 Glushkova Ave., Kyiv 252127, Ukraine \\ (3) Friedrich Schiller University, \\ Institute for Optic and Quantum Electronics, \\ 07743 Jena, Germany
}

Received June 24, 1997; Revised version October 24, 1997

The sonoluminescence of ionic semiconductors is studied. The main attention is paid to threshold phenomena which accompany the light irradiation, namely, point defect creation and nonlinear ultrasound wave attenuation. The model for the description of processes under investigation which connects the sonoluminescence excitation with the onset of point defects (vacancies and interstitials) generation by the screw dislocation with a jog moved by ultrasound is proposed. An attempt is made to estimate the parameters of crystals which define the motion of the jog in its crystal relief.

\section{Introduction}

The problems of dislocation dynamics, especially nonlinear one, and defects in crystals are still of high interest [1-5]. Among them there is a wellknown effect of acoustic waves on ionic crystals (mainly, semiconductors) which is studied and investigated in detail (see [6-9]). Sound and ultrasound (US) treatment results in the change of various important characteristics of semiconducting media which in its turn can depend upon the amplitude of acoustic waves. The most interesting here are those phenomena, when the changes induced by such waves have a threshold character, i.e. are observed when the wave amplitude reaches a certain value. One of these brightly threshold phenomena is sonoluminescence (SL), which was discovered by Ostrovskii et al. [10] (see also [11]) and represents a glow of ionic crystals subjected to US load of an overthreshold amplitude.

The analysis of SL spectra has allowed to establish [11] a large role of crystal point defects in SL excitation, the number of which essentially increases above the threshold. In such a situation it is natural to suppose generation of point defects, which could be stipulated by the motion of dislocations, and be the reason for the threshold. On the whole, the sequence of processes can be such that US shakes dislocations (edge and screw) existing in a crystal, the amplitude of their motion being proportional to the amplitude of the US wave. Thus, only free segments of the dislocations between the pinning points are oscillating. However, any new defects cannot be generated by them.

(C) Ju.M.Khalack, V.M.Loktev, A.B.Nadtochii, I.V.Ostrovskii, H.-G.Walter, 1997

ISSN 0452-9910. Condensed Matter Physics 1997 No 11 (61-70) 
There are several ways known for point defects to be created [12], one of which is climbing of jogs on screw dislocations. Other ways (for example, intersection with dislocations of the "forest") under the conditions of rather small density of dislocations should be less effective.

In the present paper an attempt is made to consider the threshold phenomena connected with the generation of defects by a driven jog on a screw dislocation. An equation of such a motion is investigated for US amplitude value up to a threshold and above it. Experimental study on amplitude relations of US damping in ionic crystals is also carried out. The results obtained are compared with the theory.

\section{Model of Nonlinear Dynamics of Dislocation with a Jog}

\subsection{Approach and Equations}

The jogs on a screw dislocation can be regarded as some kind of pinning points, which, however, unlike the ordinary ones, can under certain conditions move together with its "own" dislocation. This motion is not free, and any displacement of the jog between its initial position and the next, final one, is always accompanied by the creation of a point defect - vacancy or interstitial. This implies that such positions appear nonequivalent, and consequently the potential $W_{\text {jog }}\left(y_{\text {jog }}\right)$ of the jog proposed in Ref. [13] in contrast to the potential of the Peierls relief is not symmetrical under translations (see figure 1).

Namely this potential de-

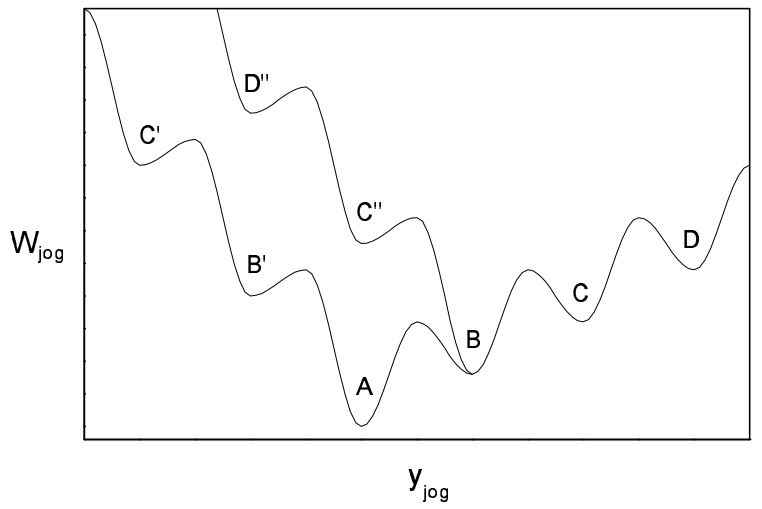

Figure 1. Potential relief of a jog in a crystal. The right- and left-hand sides of this relief correspond to the jog motion with the generation of vacancies and interstitials. termines the motion of jogs in a crystal, which we shall consider below. We should only note that the energy of the point defect creation is usually of a few eV: so the thermal overcoming of appropriate barriers by a jog is improbable. Therefore, an essential role should be played by forces due to oscillating dislocation segments, i.e. by forces of linear tension.

Let us consider the simplest case of a segment of a screw dislocation of the length $2 L$ with a jog in the middle, the ends of which are fixed on the so-called strong (i.e., immovable) pinning points. Then, (neglecting the Peierls relief that is valid for relatively high temperatures) the motion of free segments of a dislocation in a US field is described by the well-known model of an elastic string [14]; the corresponding equation of the motion may be written in the form:

$$
M_{\mathrm{dis}} \frac{\partial^{2} y}{\partial t^{2}}+B_{\mathrm{dis}} \frac{\partial y}{\partial t}-T_{\mathrm{dis}} \frac{\partial^{2} y}{\partial x^{2}}=-\sigma_{z x}^{\prime}(t) b,
$$


where $x$ is a coordinate along the dislocation, $y(x)$ is a transversal displacement, $t$ is the time, $M_{\text {dis }}$ is a dislocation mass per unit of length, $B_{\text {dis }}$ is a factor of friction, $T_{\text {dis }}$ is a linear tension of a dislocation string, $b=|\boldsymbol{b}|, \boldsymbol{b}$ is a Burgers vector, $\sigma_{z x}^{\prime}(t)$ is an appropriate (active) component of stress deviator, caused by US.

Let the jog be placed at the point $x=x_{\text {jog. }}$. Then a condition for the dislocation pinning down (at small US amplitudes) is

$$
y\left(x_{\mathrm{jog}}\right)=0
$$

At large amplitudes of an external force (i.e. of the exciting US wave) condition (2) should be replaced by an equation of a jog motion which can be written as

$$
M_{\mathrm{jog}} \frac{\partial^{2} y_{\mathrm{jog}}}{\partial t^{2}}+B_{\mathrm{jog}} \frac{\partial y_{\mathrm{jog}}}{\partial t}+\frac{\partial W_{\mathrm{jog}}}{\partial y_{\mathrm{jog}}}=T_{\mathrm{dis}}\left(\left.\frac{\partial y}{\partial x}\right|_{x_{\mathrm{jog}}+0}-\left.\frac{\partial y}{\partial x}\right|_{x_{\mathrm{jog}}-0}\right)
$$

where $M_{\text {jog }}$ and $B_{\text {jog }}$ are jog mass and the friction coefficient for it, respectively (they are, as well as $M_{\text {dis }}, B_{\text {dis }}$, phenomenological parameters), and $W_{\text {jog }}\left(y_{\text {jog }}\right)$ is the Loktev-Khalack potential (see figure 1$)$. In the general case its form depends upon all the previous positions of the jog. For example, if the letter moves from position $\mathrm{A}$ in figure 1 to position $\mathrm{B}$ with a vacancy created, the branch $\mathrm{AB}^{\prime} \mathrm{C}^{\prime} \mathrm{D}^{\prime}$ ceases to exist. In other words, the jog can return to the "initial geometry" only when passing exactly to $\mathrm{C}^{\prime}$ on the curve $W_{\text {jog }}\left(y_{\text {jog }}\right)$, for this it needs to overcome a potential barrier appropriate to the interstitial formation. Thus, it is essential that the energies of the formation of the vacancies and interstitials are definitely different; it naturally makes the potential relief $W_{\text {jog }}\left(y_{\text {jog }}\right)$ central-asymmetrical and is reflected in the jog motion under the action of a US wave.

\subsection{Threshold characteristics}

Let a US wave with the amplitude of acoustic displacement $u_{\text {ac }}$ and frequency $\omega_{\mathrm{ac}}$ spread in a crystal. Then the force per unit of length exerted on the dislocation (see (1)) is

$$
-\sigma_{z x}^{\prime}(t) b=f_{\mathrm{or}} \frac{\omega_{\mathrm{ac}} u_{\mathrm{ac}} b}{v_{\mathrm{us}}} \cos \omega_{\mathrm{ac}} t=\sigma_{\mathrm{us}} b \cos \omega_{\mathrm{ac}} t
$$

where $f_{\text {or }}$ is a factor dependent on the orientation of the US wave (on its polarization and the direction of propagation in the crystal) and $v_{\mathrm{us}}$ is a sound velocity. Under the action of force (4) free segments of the dislocation start bowing out and in accordance with the increase of $u_{\mathrm{ac}}$ a situation will set in when the amplitude of this bowing out (and consequently, the pulling forces of a linear tension exerted on the jog) will become sufficient for the jog to overcome the potential relief. The amplitude of this force is determined (see the right-hand side in Eq.(3)) by the condition

$$
\left|\frac{\partial W_{\mathrm{jog}}}{\partial y_{\mathrm{jog}}}\right|_{\max }=T_{\mathrm{dis}}\left(\left.\frac{\partial y}{\partial x}\right|_{+0}-\left.\frac{\partial y}{\partial x}\right|_{-0}\right)_{\max } .
$$


The solution of equation (1) together with (5) for the case of the external force (4) gives the following expression for the threshold amplitude of the US produced displacement:

$$
u_{\mathrm{ac}}^{\mathrm{thr}}\left(\omega_{\mathrm{ac}}\right)=\frac{v_{\mathrm{us}}}{\omega_{\mathrm{ac}}} \frac{M_{\mathrm{dis}} L}{8 f_{\mathrm{or}} b T_{\mathrm{dis}}}\left[I_{1}^{2}\left(\omega_{\mathrm{ac}}\right)+I_{2}^{2}\left(\omega_{\mathrm{ac}}\right)\right]^{-1 / 2}\left|\frac{\partial W_{\mathrm{jog}}}{\partial y_{\mathrm{jog}}}\right|_{\max },
$$

with the substitutions

$$
\begin{aligned}
& I_{1}\left(\omega_{\mathrm{ac}}\right)=\sum_{n=0}^{L / 2 b} \frac{\Omega_{n}^{2}-\omega_{\mathrm{ac}}^{2}}{\left(\Omega_{n}^{2}-\omega_{\mathrm{ac}}^{2}\right)^{2}+\left(\omega_{\mathrm{ac}} \Gamma_{\mathrm{dis}}\right)^{2}}, \\
& I_{2}\left(\omega_{\mathrm{ac}}\right)=\sum_{n=0}^{L / 2 b} \frac{\omega_{\mathrm{ac}} \Gamma_{\mathrm{dis}}}{\left(\Omega_{n}^{2}-\omega_{\mathrm{ac}}^{2}\right)^{2}+\left(\omega_{\mathrm{ac}} \Gamma_{\mathrm{dis}}\right)^{2}},
\end{aligned}
$$

and

$$
\Gamma_{\mathrm{dis}}=B_{\mathrm{dis}} / M_{\mathrm{dis}}
$$

where

$$
\Omega_{n}^{2}=\frac{\pi^{2}(2 n+1)^{2} T_{\mathrm{dis}}}{M_{\mathrm{dis}} L^{2}}
$$

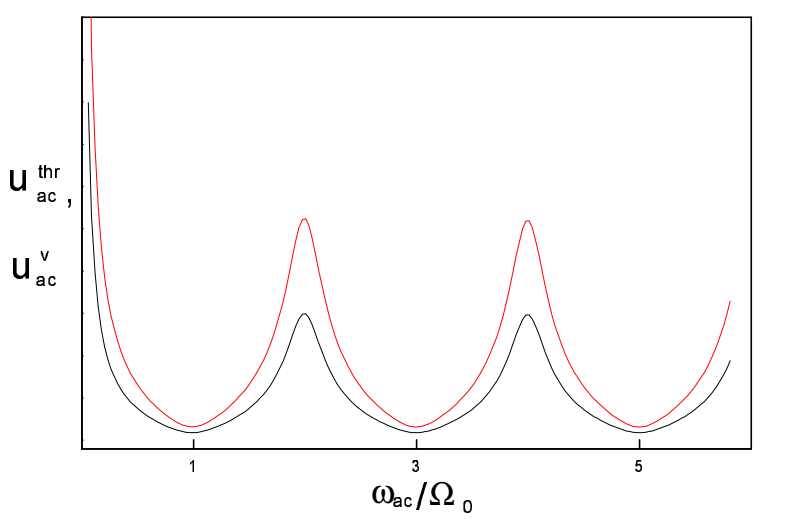

Figure 2. The dependence of threshold US amplitudes upon its frequency. The upper and lower curves describe the threshold values for interstitials and vacancy generation, respectively.

\subsection{Point defect generation}

The asymmetrical form of the curve $W_{\mathrm{jog}}\left(y_{\mathrm{jog}}\right)$ assumes that a threshold condition (5) for the jog motion with the formation of vacancies begins to hold still before an appropriate condition for the motion with interstitials formation. Then it is easy to see that for the amplitude $u_{\text {ac }}$ between these two threshold values the jog can move and does move during only one halfperiod of every period of the external force action. It means that in the 
given range of US amplitudes the jog drift happens only in one direction, and the creation of one vacancy corresponds to each its climb.

For physical reasons alone it is clear that the appearance of a vacancy gives premises for lattice relaxation in the vicinity of the defect, which should inevitably be accompanied by an acoustic emission. It is important that such an emission happens before the transition of the jog to an oscillatory mode. On the other hand, the transfer of the jog into some new position at the corresponding value $u_{\text {ac }}$ causes a reduction of the resultant forces of a linear tension along the $x$ axis. As a result, the total force will decrease, so that any further jog climbing will become impossible and the jog will stay in a new, biased, rather initial equilibrium position.

However, such a displacement also has a positive effect, namely, a reduction of the threshold US amplitude necessary for the interstitial formation. This threshold value is determined by the same formula (6), in which the value of the derivative $\partial W_{\mathrm{jog}} /\left.\partial y_{\mathrm{jog}}\right|_{\max }$ appropriate to the interstitial formation, is substituted by a half-sum of the appropriate derivatives for two opposite directions; the observable threshold for the full oscillatory jog motion is given by

$$
u_{\mathrm{ac}}^{\mathrm{thr}}\left(\omega_{\mathrm{ac}}\right)=\frac{v_{\mathrm{us}}}{8 \omega_{\mathrm{ac}}} \frac{M_{\mathrm{dis}} L}{f_{\mathrm{or}} b T_{\mathrm{dis}}} \frac{\left|\frac{\partial W_{\mathrm{jog}}}{\partial y_{\mathrm{jog}}}\right|_{\max }^{i}+\left|\frac{\partial W_{\mathrm{jog}}}{\partial y_{\mathrm{jog}}}\right|_{\max }^{v}}{\sqrt{I_{1}^{2}\left(\omega_{\mathrm{ac}}\right)+I_{2}^{2}\left(\omega_{\mathrm{ac}}\right)}} .
$$

Thus, after the beginning of the large-amplitude oscillatory jog motion (i.e. after overcoming by the amplitude $u_{\mathrm{ac}}$ of its threshold value (11)) a continuous generation of defects of the both types begins. The total number of defects generated by a jog per one US wave period above the threshold grows proportionally to the US amplitude.

\subsection{US attenuation}

Since real crystals contain dislocations of different lengths, let us consider a pure single-crystal with a network of dislocations, as well as a certain number of point defects, being the weak pinning centers for the former ones. It is also assumed that the initial concentration of point defects is small enough for the mean distance $L_{c}$ between them to be of the order of the network length $L_{N}: L_{c}^{(0)} \gtrsim L_{N}$.

If an acoustic stress of a small amplitude is applied to a crystal, dislocations are bowing out between the pinning points which results in amplitudeindependent US attenuation. At higher stresses a breakaway occurs, giving rise to hysteresis losses and consequently to the increase of US attenuation (see [14]).

But in the case under consideration $\left(L_{c}^{(0)} \gtrsim L_{N}\right)$ the increase of attenuation due to dislocation unpinning from the weak pinning centers may be negligible, so the amplitude dependence of the US attenuation may be determined by the motion of jogs on screw dislocations. When the amplitude of acoustic stress is only sufficient for the creation of vacancies, the jog merely changes its equilibrium position without any hysteresis losses. The attenuation is changed by the newly created vacancies. The latter serve as additional weak pinning centers for the dislocations, and the attenuation coefficient for a low frequency range can be found with the help of the well-known Granato-Lücke expression [14]

$$
\alpha_{\mathrm{H}}\left(\omega_{\mathrm{ac}}, \sigma_{\mathrm{us}}\right)=\frac{\omega_{\mathrm{ac}}}{2 v_{\mathrm{us}}} \frac{\Lambda L_{N}^{3}}{L_{c}} \frac{8 \mu b^{2}}{\pi^{4} T_{\mathrm{dis}}}\left[\frac{\pi f_{m}}{4 b \sigma_{\mathrm{us}} L_{c}}-1\right] \exp \left(-\frac{\pi f_{m}}{4 b \sigma_{\mathrm{us}} L_{c}}\right),
$$


where $\Lambda$ is the dislocation density, $\mu$ is a shear modulus, $f_{m}$ is the maximum value of the binding force. Here the value of $L_{c}$ is no longer equal to the initial value $L_{c}^{(0)}$, but depends on the amplitude of acoustic stress $\sigma_{\text {us }}$. In the assumption that the vacancies are uniformly distributed throughout the volume, $L_{c} \approx\left(N_{v}\left(\sigma_{\mathrm{us}}\right)+\left(L_{N}\right)^{-3}\right)^{-1 / 3}$. The number of vacancies per unit of volume is

$$
N_{v}\left(\sigma_{\text {us }}\right)=\int_{L^{v}\left(\sigma_{\text {us }}\right)}^{L_{\text {max }}} N_{\text {jog }}(L) \frac{Y\left(L, \sigma_{\mathrm{us}}\right)}{y_{0}} \mathrm{~d} L,
$$

where $N_{\text {jog }}(L)$ is the distribution function for the dislocations with jogs, $Y\left(L, \sigma_{\mathrm{us}}\right)$ is the displacement of a jog from its initial position in the US field, $y_{0}$ is a lattice spacing, and $L^{v}\left(\sigma_{\mathrm{us}}\right)$ is the minimum half-length of the dislocation, on which the jog can climb at the given value of $\sigma_{\text {us }}$. If we suggest that $N_{\text {jog }}(L)=N_{\text {jog }}=$ const, then

$$
N_{v}\left(\sigma_{\mathrm{us}}\right)=\frac{2 N_{\mathrm{jog}} L_{\mathrm{max}}^{3}}{3 \pi^{2} T_{\mathrm{dis}}} \frac{\left(\sigma_{\mathrm{us}}-\sigma_{\mathrm{us}}^{v}\right)^{2}\left(2 \sigma_{\mathrm{us}}+\sigma_{\mathrm{us}}^{v}\right)}{\sigma_{\mathrm{us}}^{2}} .
$$

For stresses high enough for the jog transition into an oscillatory mode (i.e. for $\sigma_{\text {us }}>\sigma_{\text {us }}^{\text {thr }}$ ) the attenuation of US is determined by the losses due to the creation of point defects. The attenuation coefficient for this case is

$$
\alpha_{\mathrm{jog}}\left(\sigma_{\mathrm{us}}\right)=\frac{\omega_{\mathrm{ac}}}{2 v_{\mathrm{us}}} \mu\left(W_{v}+W_{i}\right) \int_{L^{t h r}\left(\sigma_{\mathrm{us}}\right)}^{L_{\max }} N_{\mathrm{jog}}(L) \frac{\Delta y_{\mathrm{jog}}\left(L, \sigma_{\mathrm{us}}\right)}{y_{0} \sigma_{\mathrm{us}}^{2}} \mathrm{~d} L,
$$

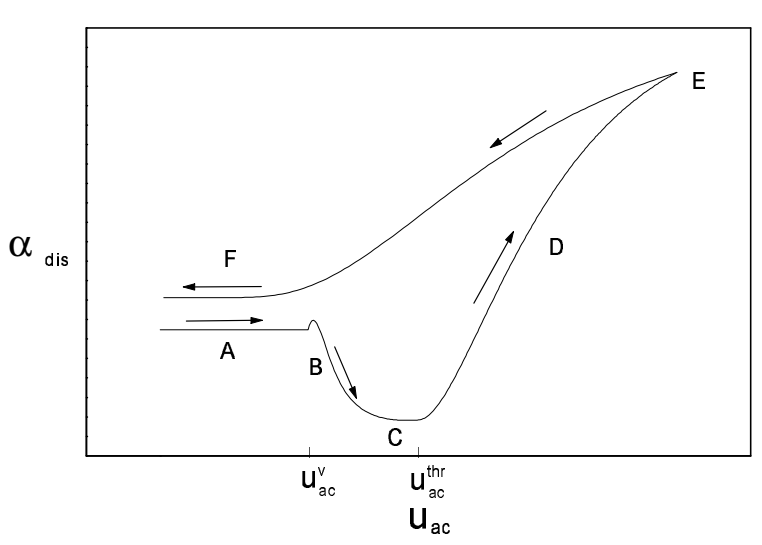

Figure 3. The general behaviour of US absorption under loading and unloading produced by a US wave.

Further the difference $\left.\sigma_{\text {us }}-\sigma_{\text {us }}^{\text {thr }}\right)$. (in as well as additional slip planes (in accordance with factor $f_{\text {or }}$ in (4)), the latter giving rise to new threshold-like pecularities in the amplitude dependence of US attenuation.

where $W_{v}$ and $W_{i}$ are correspondingly the energies of the vacancy and interstitial creation, $\Delta y_{\text {jog }}\left(L, \sigma_{\mathrm{us}}\right)$ is the amplitude of jog oscillations, and $L^{t h r}\left(\sigma_{\mathrm{us}}\right)$ is the minimum half-length of the dislocation, on which the jog oscillates. If we accept the above assumption $N_{\text {jog }}(L)=$ const, the amplitude dependence of attenuation is given by the factor

$$
\frac{\left[\sigma_{\mathrm{us}}-\sigma_{\mathrm{us}}^{t h r}\right]^{2}\left[2 \sigma_{\mathrm{us}}+\sigma_{\mathrm{us}}^{t h r}\right]}{\sigma_{\mathrm{us}}^{4}}
$$

(account

is taken of the proportionality of $\Delta y_{\mathrm{jog}}\left(L, \sigma_{\mathrm{us}}\right)$ to the difference $\sigma_{\mathrm{us}}-\sigma_{\mathrm{us}}^{\text {thr }}$ ).

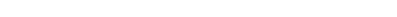


The behaviour of the attenuation during the unloading cycle is determined by the newly created defects. Additional dislocations lead to the increase of losses, while the point defects reduce losses to some extent. It is noteworthy that the amplitude dependence of US attenuation below the threshold in the case of unloading is given by expression (12) with the constant value $L_{c}$, because the jogs are fixed at some new positions and cannot create any point defect. The qualitative form of the curve of the amplitude dependence of US attenuation during the loading and unloading cycles is shown in figure 3.

\section{Experiment and Analysis}

The monocrystallyne samples $\mathrm{NaCl}, \mathrm{KCl}$, and $\mathrm{ZnS}$ (sphalerite) were experimentally studied at room temperature. The initial density of dislocations in crystals under investigation not subjected to US treatment was about $10^{4} \mathrm{~cm}^{-2}$ for $\mathrm{NaCl}$, and about $5 \cdot 10^{3} \mathrm{~cm}^{-2}$ for $\mathrm{ZnS}$. Longitudinal US waves were excited by piezoceramic transducers of the PZT type within the frequency range $1.5 \mathrm{MHz} \lesssim\left(\omega_{\mathrm{ac}} / 2 \pi\right) \lesssim 7 \mathrm{MHz}$. The factor $\alpha$ of US attenuation was measured by two techniques: 1 ) by comparing the exciting US rf-voltage $V$ with that picked up from the receiving transducer, and 2) with the help of a probing pulse by the echo-pulsing method. The US waves were excited by a continuous rf-voltage.

Typical dependence of US attenuation $\alpha$ on US amplitude taken from the sample $\mathrm{KCl}-1 \mathrm{~A}$ is shown in figure 4 . Along $\mathrm{X}$ axes the rf-voltage $V$ of frequency $f=$ $\left(\omega_{\mathrm{ac}} / 2 \pi\right)=2.5 \mathrm{MHz}$ is given. US amplitude is proportional to this voltage. It is seen that at a low amplitude $V$ the attenuation of US wave is equal to some value (point A) which remains practically constant when $V$ increases up to point B $(V \approx 10 \mathrm{~V})$. After this value of $V$ the attenuation begins to decrease (part BC of the curve). This reduction can be ex-

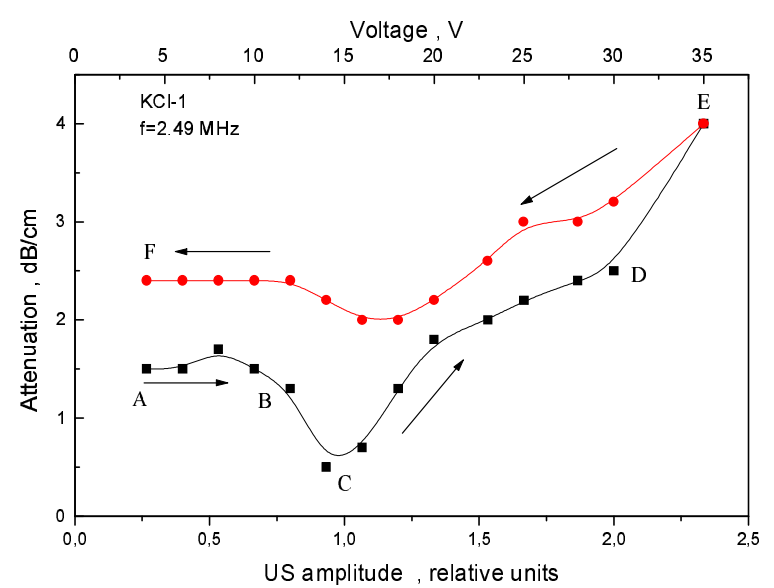

Figure 4. Experimental behaviour of US absorption by 1 st KCl sample.

plained by the threshold vacancy generation as it was described in Section 2.4 .

Part CD of this curve corresponds to attenuation growth when the generation of vacancies as well as interstitials begins (see parts BC and CD of the theoretical curve in figure 3). It is interesting to note that according to the calculations the very onset of vacancies generation is accompanied by a small attenuation increase. It can be interpreted as the result of a competition between hysteresis loss growth due to the dislocation breakaway near the "old" pinning centers and generation of new ones (vacancies), which cause free dislocation segments' slowing down. It seems that the observable 
peak in part $\mathrm{AB}$ of the experimental curve can be qualitatively ascribed to this effect. The relatively strong additional growth of attenuation (part $\mathrm{DE}$ ) is possibly provoked by the activation of dislocations with jogs motion in another slip plane, which results in one more threshold value [15].

Figure 5 represents

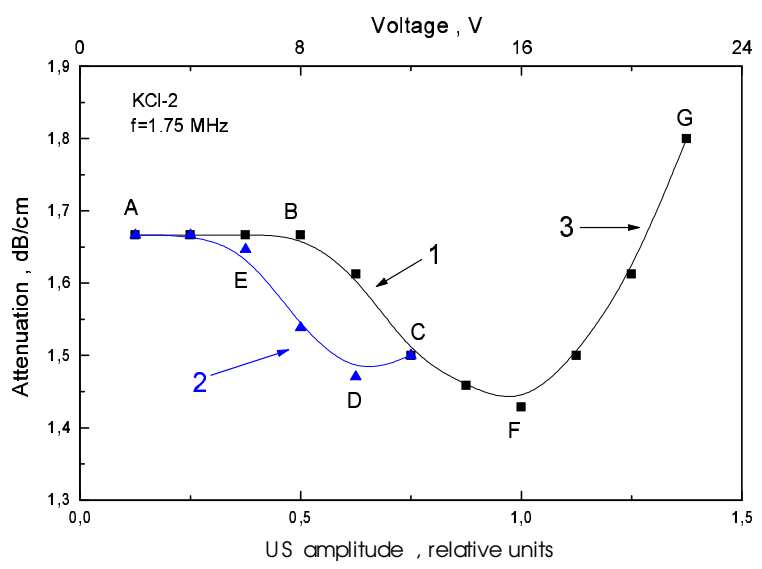

Figure 5. Experimental behaviour of US absorption by $2 \mathrm{nd} \mathrm{KCl}$ sample. on the maximum amplitude of the acoustical wave propagating in the sample. If the latter is larger than the threshold one, then the US attenuation during the unloading is greater than that for the loading because of an additional dislocation density. But if the maximum US amplitude is less than the threshold one (though sufficient for the vacancy generation), then the unloading curve is found below the loading one, in accordance with a greater number of weak pinning centers present at the moment.

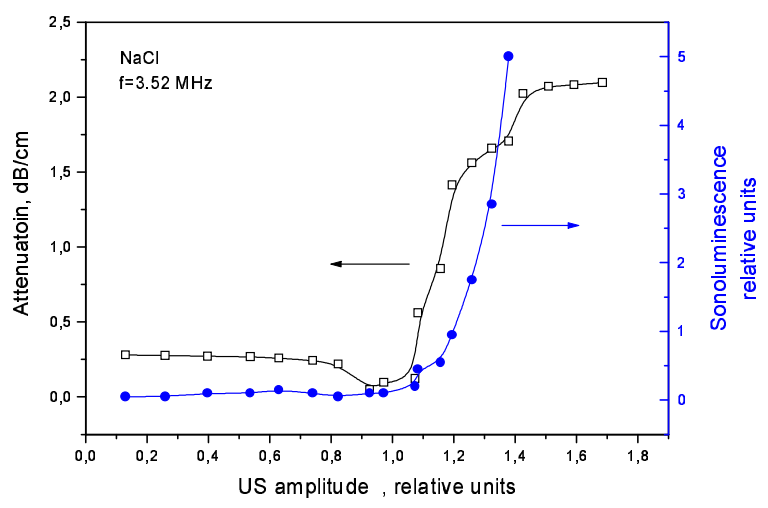

Figure 6. The comparison of threshold US amplitudes for SL excitation and for the continuous point defect generation.
On the whole, observable US attenuation is in quite a good qualitative agreement with the predictions of the proposed model. One of the most important predictions is the coincidence of the threshold of the SL excitation with that of the point defect generation. Figure 6 comfirms that such an equality, in fact, takes place (see curve 1 for SL and curve 2 for US attenuation, both of them are sharply changed at the same value of US amplitude).

Concerning the quantitative agreement between experimental and the- 
oretical curves, it should be emphasized that their shapes depend strongly on the dislocation length distribution, the character of which is not known for samples under investigation. The only quantity to be derived from these studies exactly is a ratio of the threshold values of US amplitude for continuous point defects generation and for the creation of vacancies. It gives a ratio of activation energies of the interstitial and vacancy creation by a jog by means of the following expression, as it can easily be obtained from (6) and (11):

$$
\frac{W_{i}^{*}}{W_{v}^{*}}=2 \frac{u_{\mathrm{ac}}^{\mathrm{thr}}}{u_{\mathrm{ac}}^{v}}-1 .
$$

The results of our experiments shown in figures 4 and 5 give this ratio to be about 3. Indeed, as it is seen from these figures, $\left(u_{\mathrm{ac}}^{\mathrm{thr}} / u_{\mathrm{ac}}^{v}\right) \sim 2$, where $u_{\mathrm{ac}}^{\mathrm{thr}}$ corresponds to 1 , and $u_{\mathrm{ac}}^{v}$ is $\approx 0.5$ in relative units. The relation between $W_{i}^{*}$ and $W_{v}^{*}$ is in satisfactory agreement with the values found from radiation experiments [16].

\section{Conclusions}

The main results of this work can be formulated as follows:

1. A model for the point defect generation by a jog on screw dislocation moving under the action of a US wave is proposed. It predicts the threshold character of this motion with the threshold values of the US amplitude defined by the energies of activation of the vacancy or interstitial creation. It must be, however, noticed that the simplest above approximation takes into account only one sort of vacancies and one sort of interstitials. In fact, the jog in a real crystal can generate point defects of the same type with different charges (valencies, etc.). The latter can be the reason for the observation of various impurity centre spectra in SL experiments.

2. The absorption of a US wave as a function of its amplitude has the minimum before the threshold. It has been explained with the help of supposition that new (generated by jogs) point defects (vacancies) become additional pinning centers for free dislocation segments.

3 . The experimental study of some semiconducting compounds show that observable dependencies are in satisfactory agreement with the predictions of the proposed model. It allows one to estimate some energetical crystal parameters which are in satisfactory agreement with the data obtained from independent investigations.

\section{Acknowledgement}

We are grateful to the Bundesministerium für Bildung, Wissenschaft, Forschung und Technologie, Deutchland, and the ISSEP Program of the International Soros Foundation for a partial financial support of the project.

\section{References}

[1] Sudzuki T., Yosinaga H., Takeuti S. Dislocation dynamics and plasticity. Moscow, Mir, 1989 (in Russian).

[2] Chishko K.A., Charkina O.V. Emission of electromagnetic waves by edge dislocations, moving in crystals. // Fizika Tviordogo Tela, 1996, vol. 38, No 9, p. 2775-2786 (in Russian). 
[3] Grinberg B.A., Ivanov M.A. Dominant dislocation transformations and temperature dependency of deforming stress in intermetallides. // Fizika Metallov i Metallovedenije, 1994, vol. 78, No 3, p. 3-32 (in Russian).

[4] Sugakov V.I. Accelerons and abnormal phenomena in crystals. // Preprint KIYaD-95-11. Kyiv, KINR, 1995 (in Ukrainian).

[5] Natsik V.D., Kirichenko G.I., Pustovalov V.V., Soldatov V.P., and Shumilin S.E. Influence of electronic viscosity and impurities on quantum motion of dislocations over the Peierls barriers. // Fizika Nizkih Temperatur, 1996, vol. 22, No 8, p. 965-984 (in Russian).

[6] Truell R., Elbaum C., Chick B.B. Ultrasonic methods in solid state physics. N.Y and London, Academic Press, 1963.

[7] Babentsov V.N., Gorban' I.S., Gorodetskii I.Ya., Korsunskaya N.E., Rarenko I.M., Sheinkman M.K. Influence of ultrasonic treatment on the exciton and impurity luminescence of CdTe. // Sov. Phys. Semicond., 1991, vol. 25, p. 749-750.

[8] Klimm D., Tippelt B., Paufler P., Haasen P. Ultrasonic treatment of GaP and GaAs. // Phys. Stat. Sol. (a), 1993, vol. 138, p. 517-521.

[9] Pavlovich V.N. Enhanced diffusion of impurities and defects in cristals in conditions of ultrasonic and radiative excitation of crystal lattice. // Phys. Stat. Sol. (b), 1993, vol. 180, p. 97-105.

[10] Ostrovskii I.V., Rozhko A.Kh., Lysenko V.N. Ultrasonic luminescence of CdS single-crystals. // Pis'ma v ZhETF. - 1979, vol. 5, p. 910-913 (in Russian).

[11] Ostrovskii I.V. Acoustoluminescence and crystal defects. Kiev, Vyshcha Shkola, 1993 (in Russian).

[12] Friedel J. Dislocations. Oxford, Pergamon Press, 1964.

[13] Loktev V.M., Khalack Ju.M. Threshold character of motion of the jogs on screw dislocations under the ultrasound action. // Preprint ITP-97-2U, ITP, Kyiv, 1997, 32 p. (in Russian).

[14] Granato A., Lücke K. Theory of Mechanical Damping Due to Dislocations. // Journ. Appl. Phys., 1956, vol. 27, No 6, p. 583-593.

[15] Khalack Ju. On possibility of multithreshold acoustoluminescence excitation // Ukr. Fiz. Zhurn., 1997, vol. 42, No 4, p. 499-503 (in Russian) .

[16] Luschik Ch.B., Luschik A.Ch. Electronic excitations decay with defect formation in solids. Moscow, Nauka, 1989 (in Russian).

\title{
АКУСТОЛЮМІНЕСЦЕНЦІЯ ІОННИХ КРИСТАЛІВ ЯК ЕФЕКТ АКУСТО-ОПТИЧНОГО ЗБУРЕННЯ
}

\author{
Ю.Халак, В.Локтєв, А.Надточій, І.Островський, Х.-Г.Вальтер
}

Вивчається акустолюмінесценція іонних напівпровідників. Головна увага приділяється пороговим явищам, які супроводжують випромінювання світла, а саме: утворенню точкових дефектів та нелінійному поглинанню ульразвукової хвилі. Запропоновано модель для опису розглядуваних процесів, що пов'язує збудження акустолюмінесценції з початком генерації точкових дефектів (вакансій та міжвузельних іонів) гвинтовою дислокацією із сходинкою, яка рухається під дією ультразвуку. Робиться спроба оцінити параметри, що визначають рух сходинки в її кристалічному рельєфі. 